\title{
A case series of neuroendocrine carcinoma of the stomach
}

\author{
Rao RV ${ }^{1}$, Singh Brahamjit ${ }^{1, *}$ and Sethu Babu ${ }^{2}$
}

\author{
${ }^{1}$ Department of Medical Oncology, Krishna Institute of Medical Sciences, Minister Road, Secunderabad-500003, Telangana, India \\ ${ }^{2}$ Department of Medical Gastroentrology, Krishna Institute of Medical Sciences, Minister Road, Secunderabad-500003, Telangana, India
}

\begin{abstract}
Gastric neuroendocrine carcinoma (NEC) of the stomach is rare and highly malignant carcinoma. On account of the current recognition of the disease, few case series have been reported in literature from India. Our study reports four consecutive cases of gastric NEC. Few of the interesting aspects of our study were, the early age at presentation and equivalency of occurrence of the malignancy in females, as compared with the literature available. This presentation aims to highlight the fact that the gastric NEC in our country probably have a different pattern of presentation and outcome. For validating this different behavior of gastric NEC's, more data and case series are required from our Indian subcontinent to resolve this enigma of gastric NEC's.
\end{abstract}

Keywords: Gastric neuroendocrine carcinoma; neuro endocrine carcinomas; Indian subcontinent

*Corresponding author: Dr. Brahamjit Singh, DNB Resident (Medical Oncology), Krishna Institute of Medical Sciences, Secunderabad, Telangana, Phone-9075175037; Email: drbrahamjitsingh@gmail.com

Received 10 January 2019; Revised 26 February 2019; Accepted 14 March 2019; Published 25 March 2019

Citation: Rao RV, Brahamjit S, Babu S. A case series of neuroendocrine carcinoma of the stomach. J Med Sci Res. 2019; 7(2):25-31. DOI: http://dx.doi.org/10.17727/JMSR.2019/7-6

Copyright: (C) 2019 Rao RV et al. Published by KIMS Foundation and Research Center. This is an open-access article distributed under the terms of the Creative Commons Attribution License, which permits unrestricted use, distribution, and reproduction in any medium, provided the original author and source are credited.

\section{Introduction}

Neuroendocrine carcinomas (NECs) are a very rare and a highly malignant subgroup of neuroendocrine neoplasms (NENs). Though the literature available for Gastric NECs has gradually evolved during the past few years, with changes in classification, grading system, treatment and understanding of different entities within the group, the survival of these patients remains dismal as no standard regime exists for their management [1, 2]. Further, a rise in the incidence of these carcinomas has been observed in the past few years [1]. Here we describe four cases of NEC of stomach, having a different presentation at the time of diagnosis with a brief review of literature.

NECs are rare, highly malignant subgroup of NEN's. The literature available for gastric NECs, specially with reference to the Indian subcontinent is very sparse. This presentation aims to highlight the fact that the gastric NEC in India have a different pattern of presentation and outcome. 


\section{Patient 1}

40-years-old male teacher, nonsmoker presented with persistent epigastric discomfort and weight loss of $4 \mathrm{~kg}$ in the past 3 months. On clinical examination, average built, well nourished with lone positive finding of mild pallor. Except low $\mathrm{Hb}$ $(10 \mathrm{gm} / \mathrm{dl})$ other hematological and biochemical parameters were within normal limits. Upper gastrointestinal endoscopy (UGIE) showed ulceronodular circumferential growth in the antrum causing near total obstruction (thin scope could not be negotiated), also showed changes of atrophic gastritis in fundus and body (Figure 1a). Biopsy of the lesion was suggestive of small cell neuroendocrine carcinoma, WHO grade 3 . IHC: MIB- 1 was $>50 \%$. IHC: Synaptophysin and chromogranin were diffusely positive, consistent with small cell NEC. A whole body PET-CT revealed hypermetabolic nodular enhancing circumferential wall thickening of the pyloric antrum of stomach with high uptake (Max SUV 17), with perigastric, retroperitoneal, bilateral internal iliac lymphnodes also with high FDG uptake with Max SUV of 23 (Figure 1b).

Patient was treated with 5 cycles of etoposide and carboplatin and then underwent UGIE, which showed near complete resolution of growth (Figure 1c). Repeat PET-CT also showed significant reduction in the lesion and lymphnodes (Figure 1d). He subsequently developed multiple brain metastasis after 12 months and succumbed to the disease.

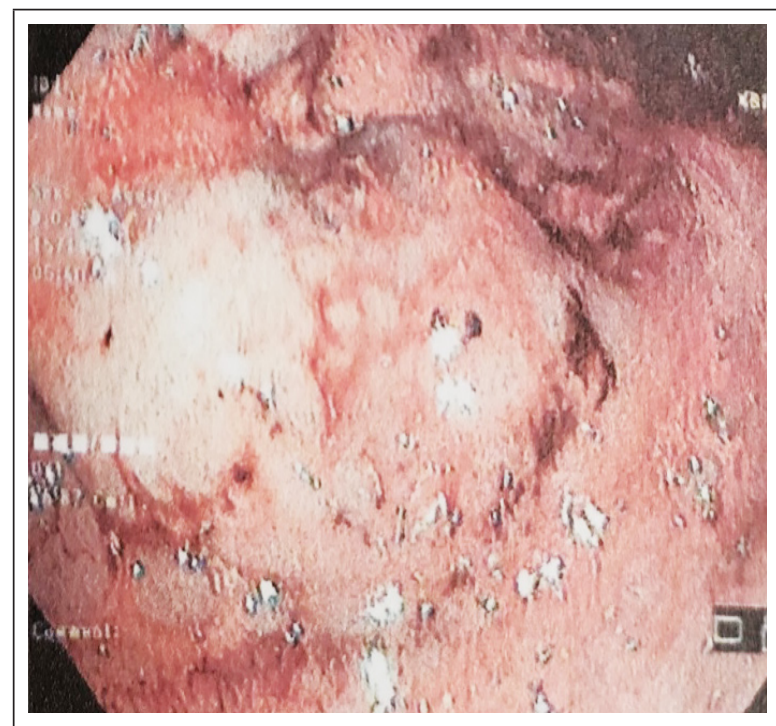

Figure 1a: Endoscopy showing a fungating exophytic growth causing gastric outlet obstruction.

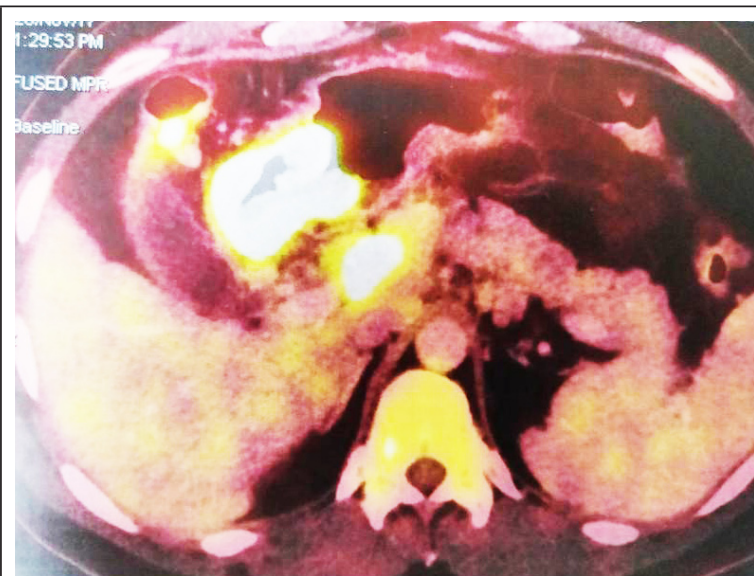

Figure 1b: PET showing hypermetabolic nodular circumferential thickening of pyloric antrum with extensive abdominal lymphadenopathy (at initial presentation).

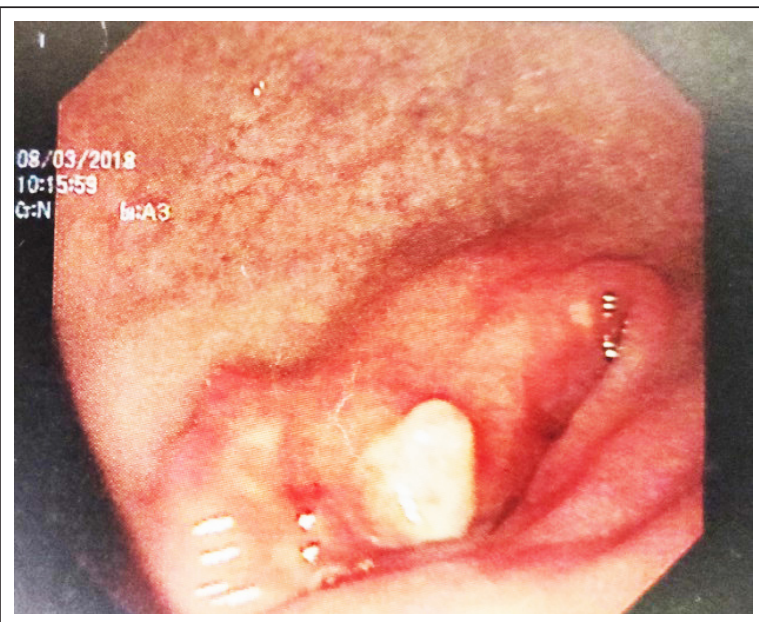

Figure 1c: Repeat endoscopy after chemotherapy showing significantly reduced lesion, now measuring not more than 1-1.5 $\mathrm{cm}$ with residual mild ulceration and nodularity.

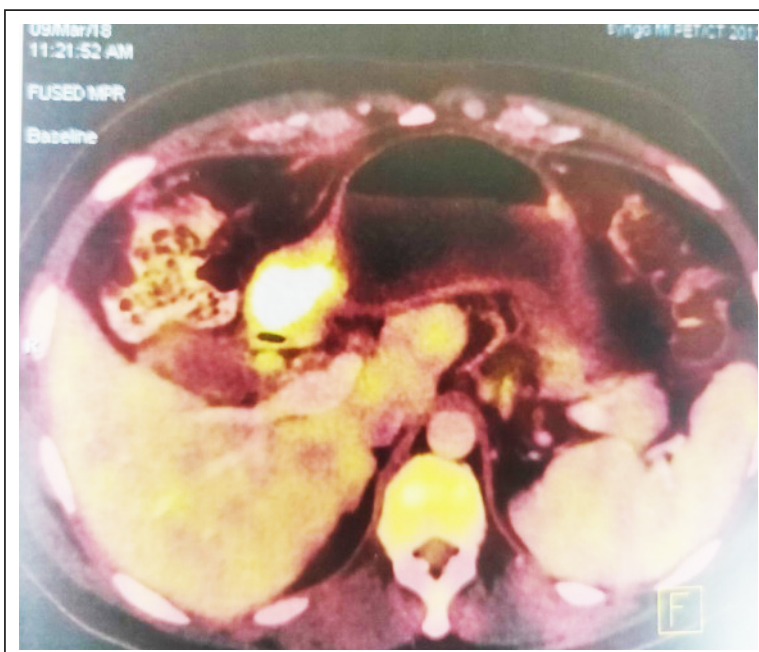

Figure 1d: PET post chemotherapy showing significant reduction in extent and metabolic activity of the tumor at the pyloric antrum. 


\section{Patient 2}

44-year-old female presented with anorexia and epigastric discomfort of one month duration. Clinically she was Eastern Cooperative Oncology Group (ECOG)-PS2, with pallor and ascites. UGIE revealed a growth in the greater curvature of stomach (Figure 2c). Biopsy from the lesion was in favor of high grade large cell NEC. On IHC, synaptophysin was positive in the tumor cells, MIB- $1>90 \%$. CECT abdomen showed a large $(7.4 \times 4.4 \times 4.3 \mathrm{~cm})$ exophytic mass arising from the greater curvature of stomach with perigastric lymphadenopathy and few omental deposits and moderate hepatomegaly $(21.1 \mathrm{~cm})$ with multiple metastases and ascites (Figure $2 b, 2 c$ ). She was treated with nab paclitaxel and carboplatin. Repeat endoscopy after 3 cycles showed significant regression of the gastric lesion (Figure 2d).

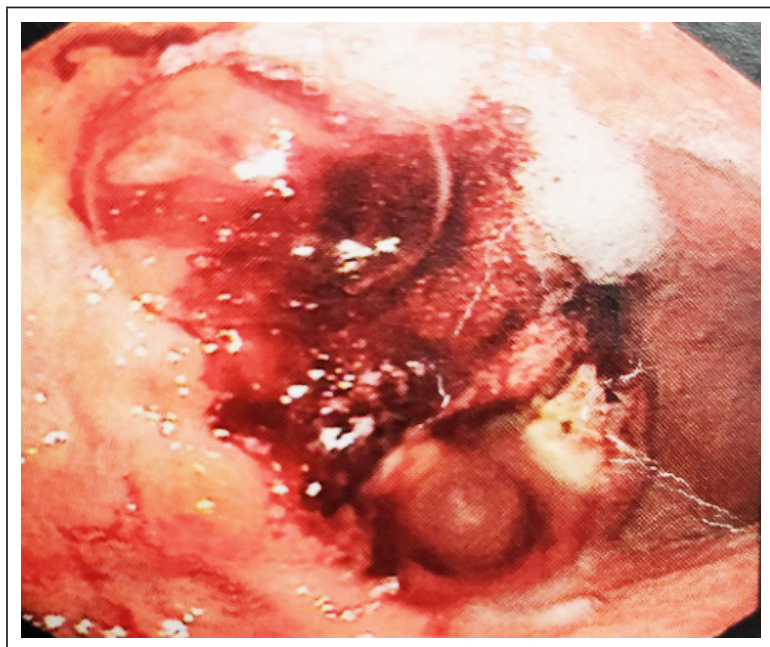

Figure 2a: Large exophytic ulceronodular growth with raised necrotic base.

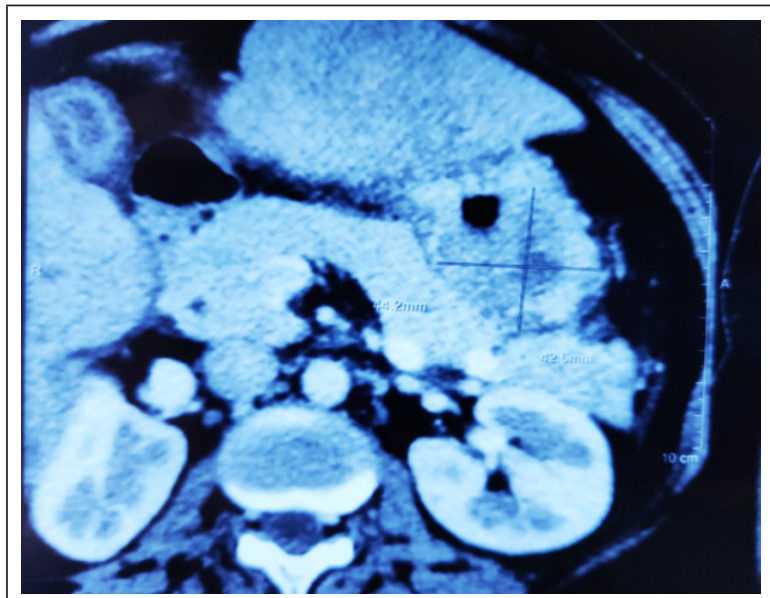

Figure 2b: Exophytic mass from the greater curvature of the stomach.
After 6 cycles of chemotherapy near total regression of the primary and liver metastases was observed on PET-CT (Figure 2d). She remained asymptomatic for duration of 11 months and then presented with multiple brain metastasis and survived for one more month.

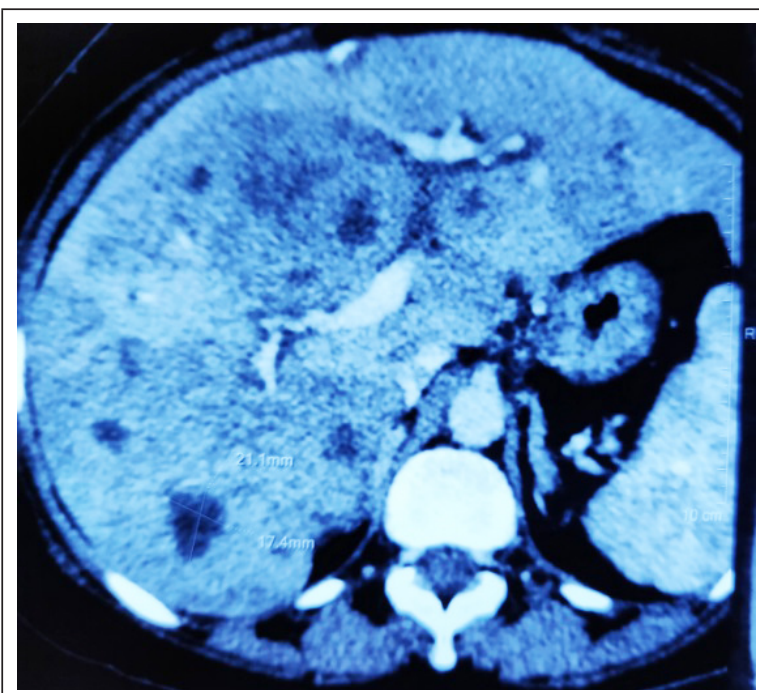

Figure 2c: Multiple liver metastasis.

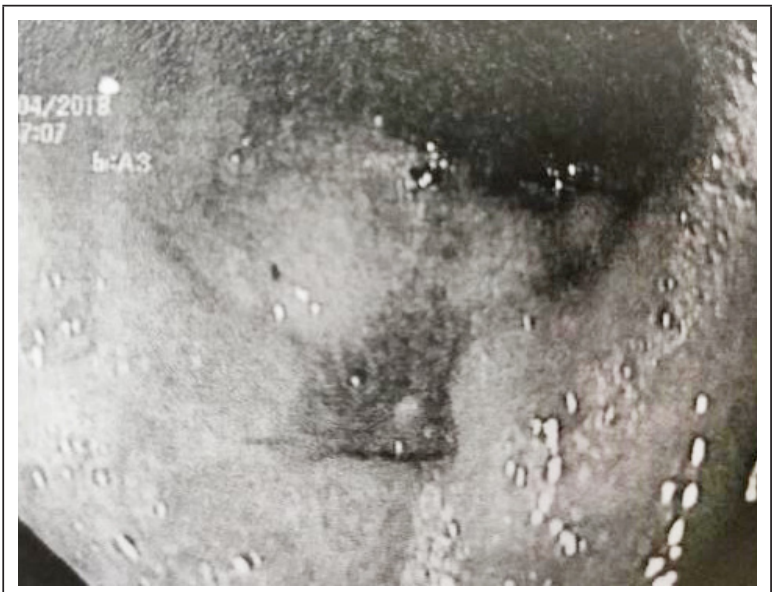

Figure 2d: Residual small ulceration and nodularity with significant regression of tumor.

\section{Patient 3}

55-years-old female presented with history of epigastric discomfort and dysphagia for the past 2 years. She was thin built, anemic with pitting edema of feet. UGIE showed a hemi-circumferential ulceronodular exophytic growth in lower esophagus and gastroesophageal junction (Figure 3a). Biopsy confirmed a small cell NEC grade III. IHC revealed synapthophysin cytoplasmic positive, Ki- $67-45 \%$. 
CECT abdomen showed a near circumferential enhancing transmural wall thickening involving lower end of esophagus measuring $5.1 \mathrm{~cm}$ and maximum single wall thickness of $18 \mathrm{~mm}$. Inferiorly the thickening was extending upto the gastroesophageal junction, with no evidence of liver metastasis. Patient underwent robotic esophagectomy with gastric pull up and feeding jejunostomy. The resected exophytic growth was $3.5 \times 3 \times 1.5 \mathrm{~cm}$, with breach of serosa and proximal resected margin $(4 \mathrm{cms})$ of the esophagus showed a focus of high grade intraepithelial squamous lesion of the lining epithelium, distal resected margin $(2.5 \mathrm{~cm})$ was free from tumor. 11 lymphnodes were dissected, largest measuring $0.5 \mathrm{~cm}$ and were negative for metastases (pT3N0M0). After complete recovery, she was treated with carboplatin and etoposide. Patient developed post-operative stricture which were dilated (Figure $3 \mathrm{~b}$ ). She remained asymptomatic for a period of 12 months and then presented with brain metastasis, and survived for 2 more months.

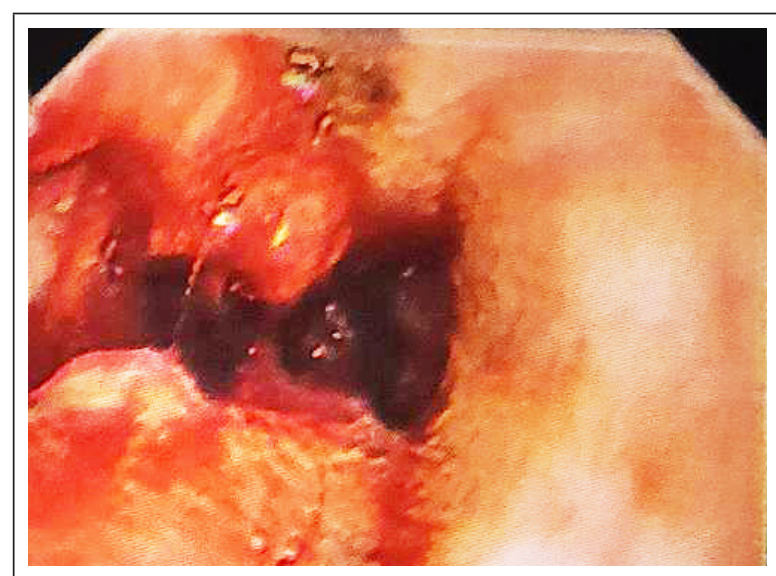

Figure 3a: Hemicircumferential ulceronodular growth in lower esophagus encroaching onto the GE junction.

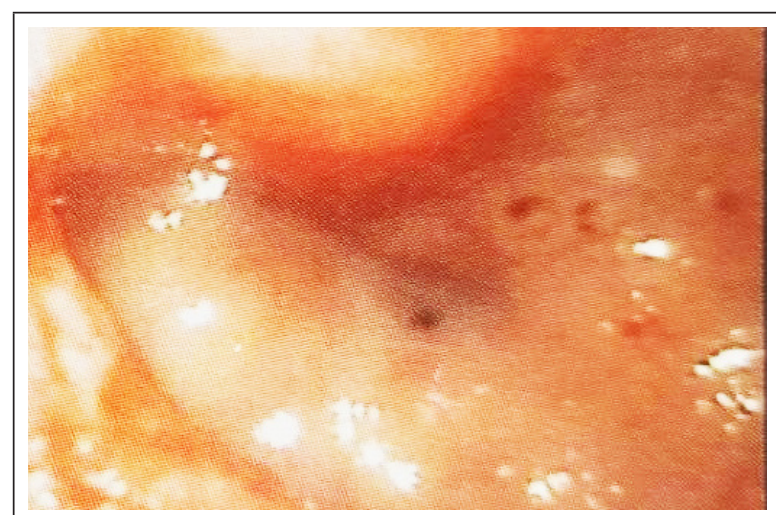

Figure 3b: Post anastamotic stricture after 7 weeks of surgery.

\section{Patient 4}

70-years-old male, known diabetic and hypertensive presented with epigastric pain and anorexia of 3 months. On examination he had mild pallor, pitting pedal oedema and mild tenderness in epigastrium. On UGI Endoscopy, there was a non-circumferential growth extending from $3 \mathrm{~cm}$ proximal to $\mathrm{GE}$ junction to $2 \mathrm{~cm}$ below GE junction (Figure $4 \mathrm{a}$ ). HPE was suggestive of high grade small cell NEC with IHC strongly positive for CK (AE1/AE3), chromogranin and focally positive for synaptophysin. Mib1-70\%. PET-CT revealed increased FDG uptake in asymmetric wall thickening involving lower esophagus and GE junction causing luminal narrowing representing primary neoplastic lesion, increased FDG uptake in left gastric lymph nodes and multiple enhancing lesions in both lobes of liver suggestive of liver metastasis (Figure 4b,c). Patient was treated with 6 cycles of carboplatin and nab-paclitaxel. Follow up UGIE and PET-CT have shown near total regression of the primary and complete resolution of tumor metastases (Figure $4 b, c, d$ ). He is presently on regular follow up for the past 15 months.

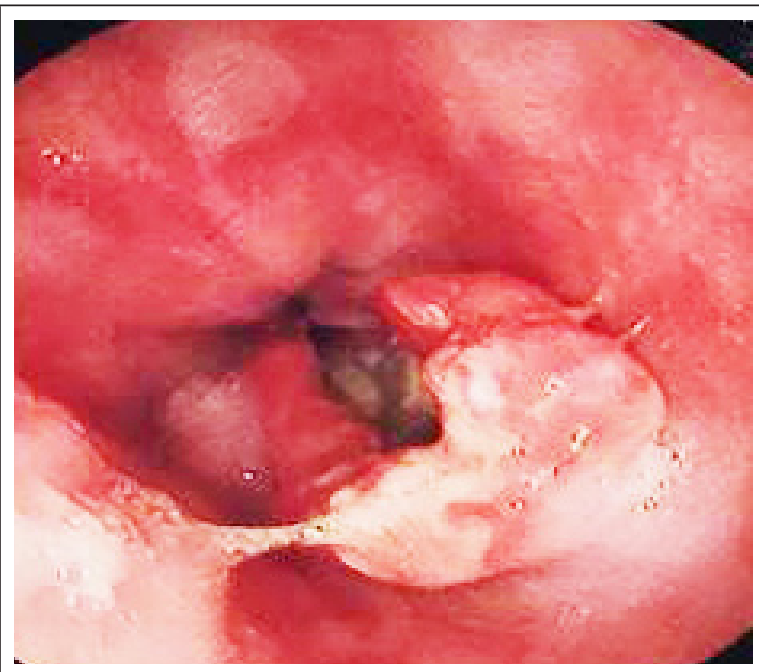

Figure 4a: Non circumferential mass at GE junction.

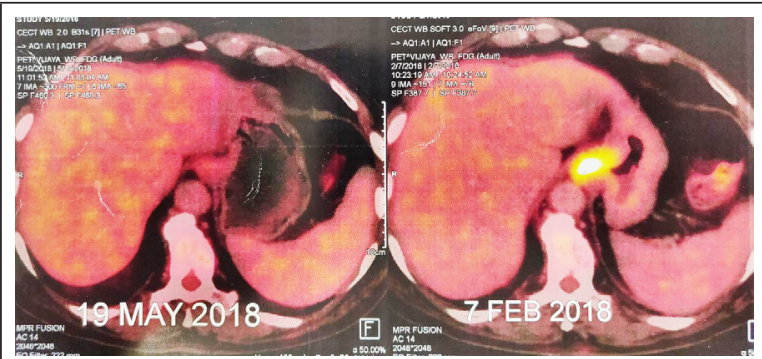

Figure 4b: PET-CT post and pre chemotherapy. 


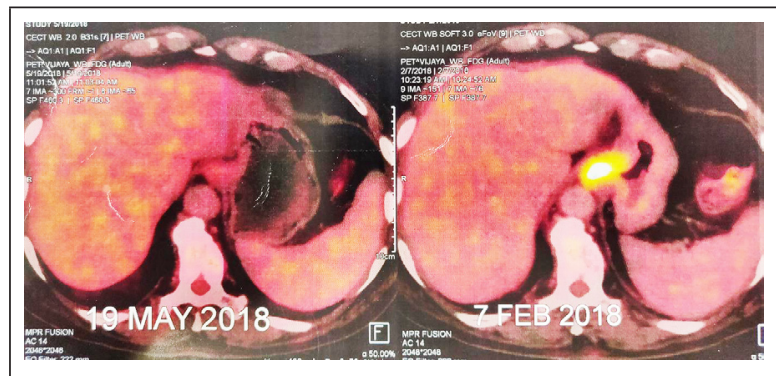

Figure 4c: PET-CT: Pre and post chemotherapy.

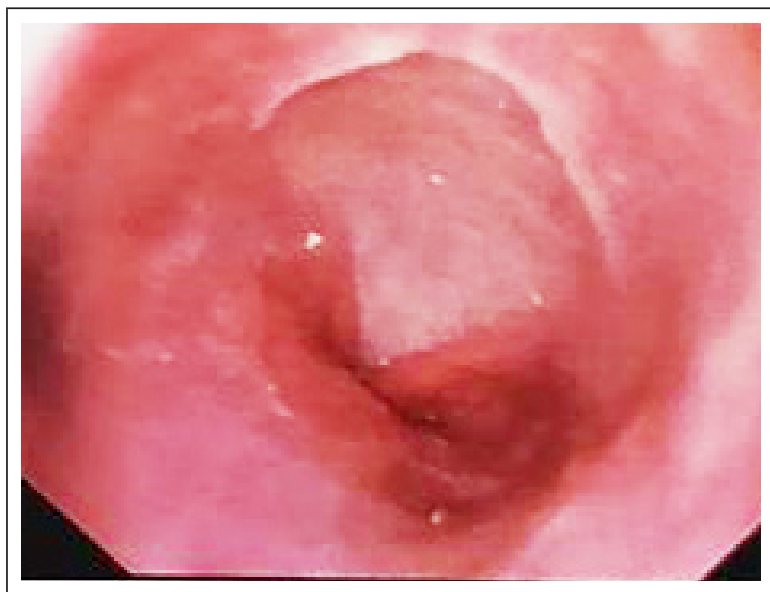

Figure 4d: UGIE showing resolution of lesion.

\section{Discussion}

Neuroendocrine carcinomas are well known but less common tumors of stomach. Neuroendocrine tumors originate from the peripheral neuroendocrine cell system and the most common location being the lungs, gastrointestinal tract and pancreas (GEP). Gastric NECs are less common and there are less than one thousand cases reported in the literature [1]. They represent up to $1.5 \%$ of resected gastric cancers [3].

Oberndorfer first differentiated neuro endocrine neoplasms from carcinomas of the gastrointestinal tract in 1907 and coined the term carcinoid. These tumors were addressed as carcinoids for nearly eight decades and even in the first WHO classification published in 1980, most of the NENs were still named carcinoids, except for endocrine tumors of pancreas and thyroid, small cell lung carcinomas and Merkel cell tumors of the skin [4].

In 2000, NENs were classified into: well differentiated neuroendocrine tumors, well differentiated NECs and poorly differentiated NECs by WHO [4]. It was finally in the 2010 classification that WHO described
GEP-NEC as a poorly differentiated, high-grade malignant neoplasm, composed of small cells or large to intermediate cells. According to this classification system the term 'Neuroendocrine neoplasm' is used to describe all tumors compromised of neuroendocrine cells and GEP NENs are categorized as NET G1, G2 or NEC3. The grading system currently used for the classification of all GEP-NENs is based on both the proliferation based grading (the Ki-67 proliferation index or mitotic count) and histopathological diagnostic criteria, where GEP-NECs have a Ki-67 index or mitotic count of $>20 \%$. If the mitotic count and Ki-67 index differ, the higher of the two is used. Histopathological grading can be combined with site-specific tumor-nodemetastasis (TNM) staging, referring to the extent of tumor spread. The final diagnosis of a NEC therefore includes the classification (NEC), the grade (G3), the relevant TNM- Stage, and cell type and functional activity [4]. The purpose of this classification is to standardize risk stratification, so that different management protocols can be analysed and definite guidelines for treatment can be established for this highly malignant and rare entity [5].

NECs can histologically be of small or large/ intermediate cell type. Large cell gastric NECs have an organoid pattern with solid nests, rosette formations or acinar structures, focal necrosis and high mitotic rate. They have a low nucleus-to-cytoplasm ratio, nuclei with evident nucleoli and vesicular chromatin, and often abundant eosinophilic cytoplasm. As a rule, synaptophysin is diffusely positive while $\operatorname{CgA}$ can be frequently negative. Small cell gastric NECs cells are most often small with dark nuclei of round or oval shape and scanty cytoplasm, forming solid sheets and nests. Staining for synaptophysin is positive in small cell NECs; however, staining for CgA can be negative. According to some studies, neuroendocrine staining is not obligatory for the diagnosis of small cell NECs because of their classical morphology [6].

Both small cell and large cell NECs can have a nonneuroendocrine component. Small cell NECs often have an undifferentiated squamous carcinoma component and large cell gastric NECs often closely resemble poorly differentiated (adeno)-carcinomas, and therefore testing for neuroendocrine markers is of great importance [5, 6]. NECs being neoplasms with neuroendocrine differentiation, their cells express various specific neuroendocrine markers 
such as chromogranin A (CgA) and synaptophysin, and less specific markers such as CD56 and neuron specific enolase (NSE). Recognition of histologic features suggestive of neuroendocrine differentiation is very critical especially as gastric NECs have a significantly worse prognosis with a higher prevalence of lymphatic and venous involvement and postoperative liver metastases than gastric adenocarcinomas [7-9]. Gastric NECs (GNECs), small cell or large cell type have a similar survival [10]. If both the adenocarcinoma and the neuroendocrine component exceed $30 \%$ of the tumour, it is then classified as a mixed adenoneuroendocrine carcinoma (MANEC) $[4,10,11]$. If however, the neuroendocrine component is less than $30 \%$ of the tumour, it is then defined as an adenocarcinoma with neuroendocrine differentiation. Many studies concerning NECs have not differentiated between NECs and MANECs [12]. A study from Ishida et al. [3] has shown that there is no statistical difference in survival between pure GNECs and GNECs with adenocarcinoma components, nor between GNEC and MANEC groups. The optimal strategy of management of MANECs is largely unknown, due to the rarity of these neoplasms. When considering treatment, the more aggressive component of MANECs should be taken into account. MANECs containing a well differentiated NET component and an adenocarcinoma component should be treated as adenocarcinomas. MANECs containing a poorly differentiated NEC component should be treated as NECs.

The four cases described met the criteria defined by the present WHO classification as patient 1 had high MiB- 1 of $>50 \%$, patient 2 MiB- $1>90 \%$, patient 3, KI-67 45\%, patient $4 \mathrm{MiB} 70 \%$. Out of the 4,3 patients were of small cell histology and 1 patient of large cell, which highlights the fact that small cell are more prevalent than large cell NECs [3].

One interesting fact of this series is that, there was female equivalence ( 2 out of 4 ) and early age of presentation ( 3 case out of 4 presenting before 60 years), unlike in most of the series, there has been a male predominance and mean age of presentation had been more than 60 years $[3,8,13]$.

Stomach GNEC's usually present with epigastric/ abdominal pain, gastro-intestinal bleeding, nausea/ vomiting, weight loss and dysphagia [14] and epigastric discomfort was a common feature of all the 4 patients, and one of the patients presented with ascites.

GNECs as per literature are most frequently located in the lower third of the stomach, with remaining tumors distributed equally between the upper and middle thirds [13]. In the present series two had gastro-esophageal junction involvement and one of antrum and one patient involved the greater curvature.

At diagnosis metastases to regional lymph nodes or liver are usually found $[3,13,14]$. In the present series regional lymphnode involvement was seen in 3 of the 4 patients and liver metastasis in two patients.

Predisposing factors associated with gastric NEC have been mentioned in only one study in literature [11], and is difficult to conclude whether smoking or excessive alcohol consumption is associated with GNECs. None of the patients in our series were a smoker or alcohol consumer and all were vegetarians.

For baseline staging and monitoring response to treatment of NEC, CT, MRI and 18F-fluorodeoxyglucose (FDG)-positron emission tomography (PET) are used routinely [15]. A review of imaging techniques found that MRI is best for imaging of liver metastases, however, for other metastases multiphase contrast enhanced CT is usually recommended and GEP-NECs appear hypo-attenuated, in contrast to NETs which are often hyper-attenuated [16].

Optimal therapy for GNECs is not established. GNECs are often treated with radical surgery [17] and adjuvant platinum-based chemotherapy, as no standard regime exists. A study from Huang et al. [18] has shown that surgery with adjuvant chemotherapy for patients with small cell gastric NEC (GSCC) can result in a median overall survival of 48.5 months in comparison to patients treated with surgery with a median overall survival of 19 months, suggesting that GNECs are chemo-sensitive tumors. There are few studies showing results of non-surgical treatment. One study has suggested the possibility of cisplatin and irinotecan as primary treatment, with response rates of $75 \%$ and PFS of 212 days with the chemotherapy regime, compared to PFS of 177 days after surgery [19]. 
Three out of the four cases in our series developed multiple brain metastasis and succumbed to disease, the fourth patient is on regular follow up. In spite of treatment, overall survival time can vary from a median of 8-33 months [11] or a mean of 14.9-40.1 months [10], with a five-year survival rate of $30 \%-$ $60 \%[3,12]$. Factors affecting survival are tumor recurrence [17] and high Ki-67 (>60\%) [17, 20].

\section{Conclusion}

The recognition of gastric neuroendocrine carcinomas has been gradually rising in the past few decades. Though significant advances have been made in their evaluation, prognostication and their management, early recognition and treatment are important in better long term outcome.

\section{Conflicts of interest}

Authors declare no conflicts of interest.

\section{References}

[1] Lepage C, Rachet B, Coleman MP. Survival from malignant digestive endocrine tumors in England and Wales: A population-based study. Gastroenterology 2007; 132(3):899-904.

[2] Korse CM, Taal BG, van Velthuysen ML, Visser O. Incidence and survival of neuroendocrine tumours in the Netherlands according to histological grade: Experience of two decades of cancer registry. Eur. J. Cancer 2013; 49(8):1975-1983.

[3] Ishida M, Sekine S, Fukagawa T, Ohashi M, Morita S, et al. Neuroendocrine carcinoma of the stomach: Morphologic and immunohistochemical characteristics and prognosis. Am J Surg Pathol. 2013, 37(7):949-959.

[4] Bosman FT, Carneiro F, Hruban RH, Theise ND. WHO Classification of tumours of the Digestive system, 4th ed.; International agency for research on cancer (IARC): Lyon, France, 2010

[5] Janson ET, Sorbye H, Welin S, Federspiel B, Grønbæk H, et al. Nordic guidelines 2014 for diagnosis and treatment of gastroeneropancreatic neuroendocrine neoplasias. Acta Oncol. 2014; 53(10):1284-1297.

[6] Shia J, Tang LH, Weiser MR, Brenner B, Adsay NV, et al. Is nonsmall cell type high-grade neuroendocrine carcinoma of the tubular gastrointestinal tract a distinct disease entity? Am J Surg Pathol. 2008; 32(5):719-731.

[7] Pape UF, Böhmig M, Berndt U, Tiling N, Wiedenmann B, et al. Survival and clinical outcome of patients with neuroendocrine tumors of the gastroenteropancreatic tract in a german referral center. Ann N Y Acad Sci. 2004; 1014:222-233.

[8] Sorbye H, Welin S, Langer SW, Vestermark LW, Holt N, et al. Predictive and prognostic factors for treatment and survival in 305 patients with advanced gastrointestinal neuroendocrine carcinoma (WHO G3): The NORDIC NEC study. Ann Oncol. 2013; 24(1):152-160.
[9] Kimura H, Konishi K, Kaji M, Maeda K, Yabushita K, et al. Highly aggressive behavior and poor prognosis of small cell carcinoma in the stomach: Flow cytometric and immunohistochemical analysis. Oncol Rep. 1999; 6(4):767772.

[10] Matsui K, Jin XM, Kitagawa M. Clinicopathologic features of neuroendocrine carcinomas of the stomach: Appraisal of small cell and large cell variants. Arch Pathol Lab Med.1998; 122(11):1010-1017.

[11] Huang J, Zhou Y, Zhao X, Zhang H, Yuan X, et al. Primary small cell carcinoma of the stomach: An experience of two decades (1990-2011) in a Chinese cancer institute. J Surg Oncol. 2012; 106(8):994-998.

[12] Kubota T, Ohyama S, Hiki N, Nunobe S, Yamamoto N, et al. Endocrine carcinoma of the stomach: Clinicopathological analysis of 27 surgically treated cases in a single institute. Gastric Cancer 2012; 15(3):323-330.

[13] Namikawa T, Oki T, Kitagawa H, Okabayashi T, Kobayashi $\mathrm{M}$, et al. Neuroendocrine carcinoma of the stomach: Clinicopathological and immunohistochemical evaluation. Med Mol Morphol. 2013; 46(1):34-40.

[14] Borch K, Ahrén B, Ahlman H, Falkmer S, Granérus G, et al. Gastric carcinoids: biologic behavior and prognosis after differentiated treatment in relation to type. Ann Surg. 2005; 242(1):64-73.

[15] Strosberg JR, Coppola D, Klimstra DS, Phan AT, Kulke MH, et al. The NANETS Consensus guidelines for the diagnosis and management of poorly differentiated (high-grade) extrapulmonary neuroendocrine carcinomas. Pancreas 2010; 39(6):799-800.

[16] Rodallec M, Vilgrain V, Couvelard A, Rufat P, O'Toole D, et al. Endocrine pancreatic tumours and helical CT: contrast enhancement is correlated with microvascular density, histoprognostic factors and survival. Pancreatology 2006; 6(1-2):77-85.

[17] Kim BS, Oh ST, Yook JH, Kim KC, Kim MG, et al. Typical carcinoids and neuroendocrine carcinomas of the stomach: Differing clinical courses and prognoses. Am J Surg. 2010; 200(3):328-333.

[18] Huang J, Zhou Y, Zhao X, Zhang H, Yuan X, et al. Primary small cell carcinoma of the stomach: An experience of two decades (1990-2011) in a Chinese cancer institute. J Surg Oncol. 2012; 106(8):994-998.

[19] Okita NT, Kato K, Takahari D, Hirashima Y, Nakajima TE, et al. Neuroendocrine tumors of the stomach: Chemotherapy with cisplatin plus irinotecan is effective for gastric poorlydifferentiated neuroendocrine carcinoma. Gastric Cancer 2011; 14(2):161-165.

[20] Boo YJ, Park SS, Kim JH, Mok YJ, Kim SJ, et al. Gastric neuroendocrine carcinoma: Clinicopathologic review and immunohistochemical study of E-cadherin and Ki-67 as prognostic markers. J Surg Oncol. 2007; 95(2):110-117. 